close look at clinical lecturer posts, and if any survive close scrutiny (and it seems likely that many will not) then they are likely to be very different. The HEFCE RAE rears its head yet again. The problem is for the university funded (as opposed to the NHS funded) clinical lecturer posts. The difficulty is quite simply that very few incumbents are sufficiently established in their research careers to allow them to be declared as 'research active' at the RAE. Inability to declare university funded posts in the RAE results in a huge financial loss, and universities up and down the country are being sorely tempted to scrap these posts. Within the present structure where most lecturer posts are locked into clinical rotations, with heavy clinical commitments, it is almost inevitable that research productivity is low. In much the same way that those involved in implementing Calman training schemes do not have the support of research or research training as a priority, so universities in the future are likely to be less concerned with funding clinical training posts that offer little opportunity for research. The very first rung on the academic ladder looks set to disappear, and universities may be very tempted to replace some clinical lecturer posts with non-clinical lecturer posts, with the dual attractions that the appointee is likely to be doing laboratory research, and will not be distracted by clinical pressures. The proposed exclusion of clinical lecturer posts from some Calman training schemes would have the same effect as withdrawal of university funding; the posts would evaporate.

Many universities have coped with severe financial pressures by a policy of non-replacement of academic staff. Clinical training grades (that is, clinical lecturers) have usually been exempt from this policy, but with the massive 1996 university budget cuts even these posts are unlikely to be spared, particularly because of their poor performance in the RAE.

Other types of recruitment into academic careers are under threat, for example due to withdrawal of MRC funding for intercalated BSc students, ${ }^{4}$ but these pressures will have an equal affect on clinical and laboratory research.

CHARITY FUNDED RESEARCH REGISTRAR POSTS

A number of medical charities have in the past funded research registrar posts. These have provided an extra pair of hands to help run the clinical service, and to do research.
However most charities are phasing these out, for two reasons. One is a preference for research money to be more clearly focused on research, notably basic science laboratory research. Another is the feeling that it is the job of the NHS to pay for the running of the clinical service. The loss of these posts has in turn caused a large drop in the number of posts available for clinical research.

PAEDIATRICS AS A SMALL AND ISOLATED SPECIALTY

We are told that as viewed by the HEFCE RAE assessment panel, academic paediatrics performs poorly compared with, for example, adult medicine. Academic paediatrics is disadvantaged by the relatively small size of the academic departments in the UK, their fragmentation from each other and from adult medicine, and (for those that are located in stand-alone children's hospitals) the geographical isolation from biomedical research on the university campus. Better integration will be needed if paediatric research (both clinical and laboratory) is to flourish in Britain.

\section{Conclusions}

The drive to improve the quality of research will leave a number of universities as casualties. Small and isolated research groups are especially under threat, posing difficulties for paediatrics because of its relatively small size in the UK. The way the RAE operates, along with a number of other factors operating simultaneously, and coupled with a general decline in clinical research, ${ }^{5}$ threaten clinical paediatric clinical research in the UK. One anxiety is that this comes at the very time that professionals, purchasers and the public are demanding more 'evidence-based' clinical practice, a goal that will be hard to achieve if clinical research is allowed to atrophy.

ANONYMOUS

\footnotetext{
1 Garfield E. How can impact factors be improved? BMf 1996;313:411-3. 2 Beecham L. Disincentives to an academic career spelt out. BMF 1996;312: 1543

3 Dean M. British medical academic work faces 'triple whammy'. Lancet 1996;347:1685.

4 Attwell D, Boyd R. Withdrawal of Medical Research Council funding for intercalated BSc students. Lancet 1996;348:198.

5 Smith R. Does Britain need an academy of medicine? BMF 1996;312:1374-5.
}

\title{
Paediatric nutrition as a new subspecialty: is the time right?
}

Scientific interest in nutrition in early life preceded the formal development of paediatrics. Building on biochemical studies of the 18 th century, ${ }^{1}$ Franz Simon underpinned a rational, scientific basis for infant feeding with his landmark work in $1838,{ }^{2}$ when the word 'paediatrics' had not even entered the English language. ${ }^{3}$ This was 20 years before the first chair of paediatrics in the US and a century before paediatric chairs were created in Britain (1930s). By then, the field of paediatric nutrition had already passed many major milestones, ${ }^{4}$ for instance the scientific understanding that led to prevention and treatment of infantile scurvy and rickets. ${ }^{56}$ In 1940 the editors of Holt's Diseases of Infancy and Childhood (11th edition) stated 'Nutrition in its broadest sense is the most important branch of paediatrics'. ${ }^{7}$ Given the extraordinary scientific effort and interest over the past two centuries, it is paradoxical that nutrition has never emerged as an independent paediatric specialty, when other areas of much more recent focus have done so.

Why should this be so? Firstly, the intensive interest in nutrition largely solved the earlier concerns. With the exception of iron deficiency anaemia, primary nutritional deficiency diseases are now uncommon in the West. Secondly, other specialties have evolved partly from the need to master specialised techniques (for example cardiac catheterisation); yet, until recently there have been few such techniques in clinical nutrition. Thirdly, medical specialties have been based traditionally on organ systems, a 
categorisation into which a broad, multidisciplinary subject like nutrition does not fit. Consequently, nutrition has been fragmented and subsumed piecemeal into other fieldsenteral nutrition into gastroenterology, intravenous feeding into surgery, growth into endocrinology and so forth.

However, there has now been a significant shift in thinking about nutrition from a preoccupation with meeting nutrient needs to a concern about its impact on health outcomes, including adult degenerative diseases, cancer, and cognitive function. ${ }^{8-15}$ After smoking, nutrition and exercise (a related province of nutrition) are purported to be the major lifestyle factors associated with cardiovascular morbidity, ${ }^{16}$ which has its origins in childhood and is the principal cause of death in the West.

Perhaps the most exciting area of current interest is the idea of 'programming'. ${ }^{17}$ This is the concept that nutrition is a key environmental influence that may act on the genome during critical periods with long term or life time effects on the organism. ${ }^{18}$ Numerous studies in animals, including primates, show that brief periods of dietary manipulation during critical or sensitive windows in early life may program outcomes of considerable public health and clinical significance were they to apply to humans, including lifelong effects on lipid and carbohydrate metabolism, body fatness, blood pressure, development of atherosclerotic lesions, and neurodevelopment. ${ }^{19-23}$ Indeed recently, experimental and epidemiological studies now strongly indicate that early nutrition is a key factor for such outcomes in humans. ${ }^{81415}$

Concurrently, increasing evidence supports the view, discussed in this article, that effective clinical nutritional management in paediatrics may have more immediate influence on progression of major disease states, disease complications, response to treatment, and on hospital admissions or their duration. ${ }^{24-28}$

This refocusing of paediatric nutrition towards the impact of nutrition on both immediate and long term health has drawn new bioscientific, clinical, epidemiologi$\mathrm{cal}$, and health economic expertise into the field. The evidence on the importance of early nutrition has critical implications for public health and clinical practice, and for service providers and purchasers.

A case for paediatric nutrition as a distinct specialty Given this new direction, the issue now is whether paediatric nutrition should be a recognised discipline within paediatrics. In approaching this, I shall address three general questions: is there an academic case, a clinical case, and a financial one?

(1) Academic case: are there readily identifiable deficiencies in current nutritional practice, education, and research that would benefit from academic development of the field?

- With few 'nerve centres' in paediatric nutrition, an agreed standard of clinical practice has not developed and paediatricians have had to acquire nutritional skills in an $\mathrm{ad}$ hoc way. Not surprisingly, clinical opinion and therefore patient management varies greatly. Standards of nutritional practice in the community have been equally inconsistent. Various official and semiofficial recommendations have been conflicting and patchily understood. And while advisory bodies attempt to carve out more consistent, evidence-based nutrition policy, there are few recipients for such advice in terms of centres that can secondarily process and disseminate key messages to practitioners. The result is professional and parental uncertainty over nutritional care.

- Education in paediatric nutrition has been recognised as a priority area for development. As yet it remains deficient at every stage: preclinical, clinical, and postgraduate.
Higher training in nutrition would generally depend on chance local interests.

- A key objective for clinical research should be to prove outcome benefits for recommended managements. Yet the critical issue of whether early nutrition influences health outcomes or development has, only recently, been formally approached. Disturbingly, most recommendations of expert bodies on fundamental areas of practice must be based, largely, on theoretical considerations. These deficits sharply contrast with the major research investment in nutritional physiology, which has received more research attention than any other area of paediatrics. For instance, as far back as 1953, Macy reviewed over 1500 publications on breast milk composition ${ }^{29}$ - just one small area of infant nutrition. This profusion of nutritional studies in the face of the paucity of outcome data justifying clinical practice implies that clinical nutritional research has lacked direction.

It seems reasonable to expect that the focusing of clinical research and the need to develop consistent standards of clinical practice, education, and training in paediatric nutrition would now be best served by formal development of the discipline.

\section{(2) Clinical case: are there defined areas of paediatric} nutritional practice that require specialised attention and expertise?

Certainly, even with good paediatric dietetic services. Nutritional advice is probably the commonest category of advice sought by parents. In clinical paediatrics, nutrition is one of the major problem areas - virtually every sick infant in neonatal intensive care and a significant proportion of sick children could benefit from more specialised nutritional attention. In some situations, including iron deficiency anaemia, obesity (incidence now increasing apace), and long term parenteral nutrition, nutrition may be the principal clinical issue.

Malnutrition, unacceptably often identified in hospitalised medical and surgical patients of all ages, if not effectively treated by enteral or parenteral nutrition, may increase infection risk, reduce wound healing, increase the need for high dependency or intensive care, increase hospital stay, and increase risk of complications or death. ${ }^{27} 28$

A recent review by Booth emphasises that intensive intragastric or transpyloric feeding is effective in inducing remission, promoting long term growth and reducing relapses in Crohn's disease; can arrest pulmonary deterioration in cystic fibrosis; possibly reduces spasticity in cerebral palsy; reduces need for surgery in gastrooesophageal reflux, and improves the clinically important malnutrition that accompanies chronic liver disease, congenital heart disease, and malignancies. ${ }^{24}$ Ledermann and coworkers show that intensive nutritional management of children with renal disease has a major impact on growth and symptoms of renal failure ${ }^{25}$ and probably reduces hospital stay, the need for more expensive treatments (for example growth hormone), and may delay the need for renal dialysis.

In preterm infants, the complex enteral nutritional management required may reduce very expensive hospital stay and may significantly increase later neurodevelopment and IQ (A Lucas et $a l^{1415}$ and unpublished), with important implications for these babies' future education and employment.

Formal organisation and provision of clinical services with a multidisciplinary nutrition team has been shown to reduce catheter sepsis, metabolic complications, and clinical outcome. ${ }^{27}{ }^{28}$ For instance, Puntis and coworkers 
showed that specialised training of staff in a children's hospital dramatically reduced catheter sepsis from $45 \%$ to $8 \%{ }^{26}$

Furthermore, new specialised nutritional techniques are becoming suitable for clinical use. They include calorimetry, isotope probes (for instance the dual isotope approach to energy expenditure ${ }^{30}{ }^{31}$ ), a wide range of non-invasive or minimally invasive body composition techniques, methods for assessment of bone mineral content (for example dual $x$ ray absorptiometry), and sophisticated anthropometric tools. These techniques require specialist training and a new generation of motivated clinicians to pioneer their use in practice.

There appears, therefore, to be a convincing clinical case for specialised nutritional services and training in paediatric nutrition. Without these, many children will receive suboptimal care, with implications for their wellbeing, prognosis, and long term outcome.

(3) A financial case: are there compelling data for purchasers? The clinical case outlined above has important cost implications. The evidence that good training and service provision in nutrition can reduce hospital admissions, the length of hospital stay, the level of care required and costly complications of treatment, is likely to be an important factor in the development of the field.

In recent publications, for instance, the British Association for Parenteral and Enteral Nutrition have derived several worked examples, albeit in adult patients, of expected cost savings achieved by nutritional interventions and provision of specialised services. ${ }^{27}{ }^{28}$ Thus, provision of nutritional support to undernourished patients in hospital could save, conservatively, a national expenditure of $£ 266$ million/ year and the estimated cost saving provided by a nutrition team in preventing catheter sepsis alone is in the range $£ 1650$ to $£ 5000$ per septic episode.

Numerous areas of potential cost savings need to be derived more specifically for the paediatric population, but it seems likely that investment in paediatric nutrition would be richly rewarded.

\section{Is the time right?}

Yes and no. The biological, epidemiological, and clinical research that now underpins the importance of early nutrition, the need to improve standards of practice, education, and training and the potential financial benefits of formal nutritional services, could be seen as immediate signals for the development of the field. However, it seems unlikely that this will happen out of the blue. Prerequisites include: - Further collation of data on clinical service needs and on the cost savings of providing them to develop a widely accepted and compelling case for purchasers - though the foregoing provides a basis for such a case.

- Development of 'centres of excellence' to provide academic training for new specialists in nutrition.

- Nutrition education and training as a prominent part of the professional development of every future consultant; and for those intending to specialise, more intensive nutrition education made available, for instance masters or diploma training.

- Development and reorganisation of clinical services in all paediatric units to provide a nationally consistent standard of care and suitable milieu for the acquisition of clinical expertise by paediatricians, dietitians, nurses, and related professionals. Specific allocation of nutrition beds in larger centres could provide for management of more difficult cases and a focus for training. Initially the running of nutrition services would inevitably be steered by those with pre-existing expertise (for example gastroenterologists and surgeons), but with gradual increase in prominence of a new breed of paediatric nutrition specialists entering the field de novo.

\section{What would a specialist in paediatric nutrition actually do?}

Such specialists would lead the nutrition team in collaboration with dietitians, providing nutritional advice across the specialties and in intensive care units, manage specific nutritional problems (inpatient and outpatient), provide regional advice on nutrition, use and develop specialised investigative facilities (body composition tools, energy metabolism techniques, isotope probes, etc), liaise with dietitians and paediatricians to develop clinical nutrition policies, develop community services for nutritional management (for example home parenteral nutrition, post-discharge nutrition of preterm infants, etc), set up training programmes for health professionals in hospital and community and undertake audit. Such specialists would facilitate clinical research that underpins public health and clinical practice.

\section{Will it fly?}

Sooner or later, yes. Various US centres are considering this direction, though no formal development has taken place. Britain, with its unusual and long standing confluence of expertise, may be best placed to spearhead the development of academic paediatric nutrition.

Clearly, if we think infant and childhood nutrition matters, both in the short term and for later health and development, then it can no longer be seen as a secondary issue or simply a matter of personal choice and we need to rationalise and improve current practice.

\section{ALAN LUCAS}

MRC Childhood Nutrition Research Centre,

Institute of Child Health,

30 Guilford Street,

London WC1N $1 E H$

1 Underwood M. A treatise on to diseases of children. 4th Ed. London: J Matthews, 1979

2 Simon JF. Mother's milk and its chemical and physical properties. Dissertation (in Latin). Berlin, 1838 .

3 Jacobi A. Contributions to midwifery and diseases of women and children, with a report on the progress of obstetrics, uterine and infantile pathology. 1859.

Pearson HA. The centennial history of the American Pediatric Society 1888-1988. New Haven, Connecticut: Yale University Printing Service, 1888-1988. New Haven, Connecticut: Yale University Printing Service,

5 Holst $\mathrm{H}$, Froelich T. Experimental studies relating to ship beri-beri and scurvy. Fournal of Hygiene 1907:7;634-9.

6 Huldschinsky K. Heilung von Rachitis durch Kunstliche Hohensonne. Dtsch Med Wochenschr 1919:45:712-7.

Holt LE, Howland J. Holt's diseases of infancy and childhood. 11th Ed. New York: D Appleton-Century Company 1940:139-66.

8 Barker DJP. Fetal nutrition and cardiovascular disease in adult life. Lancet 1993:341;938-41.

9 Barker DJP, Winter PD, Osmond C, Margetts B, Simmonds SJ. Weight in infancy and death from ischaemic heart disease. Lancet 1989;ii:577-80.

10 Cooper C, Crawley M, Bhalla A, et al. Childhood growth, physical activity and peak bone mass in women. $\mathcal{F}$ Bone Miner Res 1995;10:940-7.

11 Barker DJP. Growth in utero, blood pressure in childhood and adult life, and mortality from cardiovascular disease. BMf 1989;298:564-7.
marker

12 International Agency for Research in Cancer. Cancer, causes, occurrence and International Agency for Research in Cancer. Cancer, causes,
control. (Scientific Publication No 100.) Lyon: IARC, 1990.

13 Ravelli GP, Stein Z, Susser MW. Obesity in young men after famine exposure in utero and early infancy. $N$ Engl f Med 1976;295:349-53.

14 Lucas A, Morley R, Cole TJ, et al. Early diet in preterm babies and developmental status at 18 months. Lancet 1990;335:1477-81.

15 Lucas A, Morley RM., Cole TJ, Lister G, Leeson-Payne C. Breast milk and subsequent intelligence quotient in children born preterm. Lancet 1992;339:261-4.

16 Committee on Clinical Practice Issues in Health and Disease. The role and identity of physician nutrition specialists in medical school-affiliated hospitals. Am f Clin Nutr 1995;61:264-8.

17 Lucas A. Role of nutritional programming in determining adult morbidity. Arch Dis Child 1994:71:288-90.

18 Lucas A. Programming by early nutrition in man. In: Bock GR, Whelan J, eds. The childhood environment and adult disease. (CIBA Foundation Symposium 156.) Chichester: Wiley, 1991:38-55.

19 Smart J. Undernutrition, learning and memory: review of experimental studies. In: Taylor TG, Jenkins NK, eds. Proceedings of XII International studies. In: Taylor TG, Jenkins NK, eds. Proceedings of
Congress of Nutrition. London: John Libbey, 1986:74-8. 
20 Snoek A, Remacle C, Reusens B, Hoet JJ. Effect of a low protein diet during pregnancy onto fetal rat endocrine pancreas. Biol Neonate 1990;57:107-18. and adipose tissue enzymes in adult rodents. 7 Nutr 1984;114:1231-4.

22 Lewis DS, Bartrand HA, McMahan CA, McGill HC Jr, Carey KD, Masoro Lewis DS, Bartrand HA, McMahan CA, McGill HC Jr, Carey KD, Masoro
EJ. Preweaning food intake influences the adiposity of young adult baboons. F Clin Invest 1986;78:899-905

23 Mott GE, Lewis DS, McGill HC. Programming of cholesterol metabolism by breast or formula feeding. In: Bock GR, Whelan J, eds. The childhood environment and adult disease. (CIBA Foundation Symposium 156.) Chichester: Wiley, 1991:56-76.

24 Booth IW. Enteral nutrition in childhood. Br f Hosp Med 1991;46:111-3.

25 Ledermann SE. The impact of nutrition on growth in chronic renal failure: revisited 1996. Plenary abstracts. Proceedings of the British Paediatric Association Annual Meeting. London: BPA, 1996 Vol 68:22.

26 Puntis JWL, Holden CE, Smallman S, et al. Staff training: a key factor in reducing intravascular catheter sepsis. Arch Dis Child 1991;6:335-7.
27 Silk DBA, chairman and editor. Organisation of nutritional support in hospitals. A report by a working party of the British Association for Parenteral and A report by a working party of the British Assoc

28 Elia M, chairman and editor. Enteral and parenteral nutrition in the community. A report by a working party of the British Association for Parenteral and Enteral Nutrition (BAPEN). November 1994.

29 Macy IG, Kelly HJ, Sloan RE. The composition of milks. National Research Council Publication No 254. Washington, DC: National Academy of Sciences 1953.

30 Schoeller DA, Ravussin E, Schutz Y, Acheson KJ, Baertschi P, Jequier E. Energy expenditure by doubly labelled water: validation in humans and proposed calculation. Am f Physiol 1986;250:R823-30.

31 Roberts SB, Coward WA, Schlingenseipen K-H, Nohria V, Lucas A. Comparison of the doubly-labelled water $\left({ }^{2} \mathrm{H}_{2}{ }^{18} \mathrm{O}\right)$ method with direct calorimetry and a nutrient-balance study for simultaneous determination of energy expenditure, water intake, and metabolizable energy intake in preterm infants. Am 7 Clin Nutr 1986;44:315-22.

\section{Interventional cardiology}

Over the last 15 years the treatment of congenital heart defects has changed from being primarily surgical to a combination of interventional cardiology and surgery. Although interventional cardiology has replaced surgery for a number of defects, it has also provided an additional and complementary treatment to surgery for many conditions.

The cardiovascular system can be viewed as a pump with attached blood vessels. Major 'replumbing' such as the arterial switch operation for transposition of the great arteries remains the province of the surgeon, while dilations and occlusions are increasingly performed in the cardiac catheterisation laboratory. The heart also has an electrical system that may be disturbed by pacemaker failure, conduction defects, or unwanted electrical circuits and interventional electrophysiology is now an important part of interventional cardiology.

\section{Dilations}

Dilations are among the commonest interventional cardiology procedures and stenoses of all structures and blood vessels have been subjected to dilation. Balloon atrial septostomy was introduced by Rashkind and Miller over 30 years $\mathrm{ago}^{1}$ and remains in use in its original form to improve mixing in patients with transposition physiology and for patients who require venting of an atrium whose outflow is restricted. Atrial septostomy in older patients, whose atrial septum can be much tougher, can be accomplished by first cutting the atrial septum with a blade. ${ }^{2}$ The development of plastic cigar shaped balloon dilation catheters by Gruntzig et $a l^{3}{ }^{3}$ initially for peripheral and coronary arteries, represented the turning point for interventional cardiology. Larger diameter balloons were made for the larger central vessels and cardiac valves in children. These large diameter balloon dilation catheters (valvuloplasty catheters) were first used to treat pulmonary valve stenosis ${ }^{4}$ and balloon dilation is now the treatment of choice for pulmonary stenosis in all age groups. The aim of the procedure is to ablate the valve, as the resultant pulmonary regurgitation is mild and well tolerated. Valvuloplasty has been especially useful in neonates with critical pulmonary stenosis where surgery previously carried a high mortality. ${ }^{5}$ In neonates with the more extreme form of pulmonary atresia with intact ventricular septum, valvuloplasty can still be accomplished by first perforating the pulmonary valve with a hot wire. ${ }^{6}$ Surgery is employed only for dysplastic valves in patients with Noonan's syndrome who also have small valve rings. Balloon pulmonary valvuloplasty can also alleviate cyanotic spells in patients with tetralogy of Fallot whose pulmonary arteries are not yet large enough to safely undergo primary repair. ${ }^{7}$ Aortic valve stenosis can also be treated by balloon dilation ${ }^{8}$ but greater caution is required because overdilation (which is routinely employed in pulmonary stenosis) can result in significant aortic regurgitation and earlier valve replacement. Balloon dilation of the mitral valve is especially useful for rheumatic mitral stenosis but may also be helpful in congenital mitral stenosis, ${ }^{9}$ which remains a difficult condition to treat because usually there are multiple anomalies in the valve apparatus. Balloon dilation of coarctation of the aorta is used for both native ${ }^{10}$ and postsurgical coarctation where it is generally considered to be the treatment of choice. Its efficacy in native coarctation depends on the age of the patient and whether there is significant underdevelopment of other parts of the aortic arch. Neonates in whom the ductal tissue forms a sling around the arch have a good initial response to dilation but a high restenosis rate ${ }^{11}$ probably because of later contraction of ductal tissue. Older patients have a good response to balloon dilation. ${ }^{12}$ However overdilation may result in aneurysm formation. ${ }^{13}$ Dilation of pulmonary artery stenoses either native or acquired is useful in a percentage of patients. ${ }^{14}$ Vessel recoil and the risk of overdilation of distal tapering pulmonary arteries limits the clinical usefulness of pulmonary artery angioplasty. These problems have been addressed by the introduction of endovascular stents which were developed to treat peripheral vascular disease in adults. ${ }^{15}$ Stents are usually expanded by a balloon into a lattice-like structure that lines and supports the vessel wall. This has been a particularly important development for many postoperative and some preoperative patients with pulmonary artery stenoses in which the results of surgical reoperation can be disappointing. ${ }^{16}$ Implantation of stents can be technically challenging and may require further dilation to allow for growth if implanted in younger children. ${ }^{17}$ The stents usually develop a neointima which can be excessive, if the stent is not fully dilated throughout its length, and result in restenosis. Nevertheless the increase in vessel diameter produced by stents is significantly greater than that usually produced by angioplasty. Stents have also been used to successfully treat native coarctation in older patients, baffle stenoses in patients after a Mustard operation, and stenotic collateral arteries in patients without true central pulmonary arteries.

Medical manipulation of the arterial duct transformed the management of neonates in the late 1970s. Angioplasty of the arterial duct has been used for the rare duct dependent patient who fails to respond to prostaglandin infusions. ${ }^{18}$ Stents have also been used to maintain ductal patency in patients with hypoplastic left heart syndrome or pulmonary atresia. However restenosis of the relatively 